\title{
Application of the statistical reverse method for the lithological analysis of bituminous deposits
}

\author{
Ekaterina Yachmeneva* \\ Kazan Federal University, Institute of Geology and Petroleum Technologies, 420008 Kazan, Russian \\ Federation
}

\begin{abstract}
The studied deposit is located on the territory of the Republic of Tatarstan (Russia). The reservoir formation is represented by bituminous sandstone. The deposit is being developed by steam-gravity drainage (SAGD). The researchers noted that the reservoir has the variability of petrophysical parameters in thickness. The correct adjustment of the lithological model will allow us to assess the variability of the reservoir characteristics by its thickness, which can better predict its reservoir and elastic properties. The article presents the results of the modeling of the mineralogical composition of rocks and the coefficient of total porosity. Results received using the statistical reverse method of constructing a volume model. This method is based on geophysical well logging used to predict the content of rock-forming components of the studied sediments. The use of core data, in particular X-ray phase analysis, made it possible to evaluate the results of the lithological model.
\end{abstract}

\section{Introduction}

Since the beginning of the 70 s of the 20th century, research and experimental-industrial work has been carried out on the deposits of heavy oils and natural bitumen in the Republic of Tatarstan (Russia). Based on the study of foreign experience, TatNIPIneft researchers decided that thermal methods of impact on the formation can be used to develop such deposits [1]. The object of study is occurring of the Permian. It is developing by the method of steam-gravity drainage. This method of developing the efficiency of hydrocarbon extraction largely depends on the possibilities of fluid movement in the productive reservoir. In this regard, determining the mineralogical composition and petrophysical characteristics of the reservoir rock and the surrounding formations is becoming more relevant.

The article is devoted to developing an algorithm for constructing a volumetric lithological model of bitumen-saturated rocks of the Ufa stage of the Permian system.

\section{Object and methods of research}

\footnotetext{
* Corresponding author: EAYachmenjova@gmail.com
} 
The productive sediments of the object of study occur to the Ufa stage of the Permian system. In the layer, the lower - sand-clay and upper - sand units are distinguished. The sand unit is composed of weakly cemented and unconsolidated sands and sandstones. The detrital material contains grains of feldspar, quartz, and mica [2]. The cementitious substance is mainly high-viscosity oil, but the carbonate component of the cementitious substance is also present. The depth of the reservoir formation varies between 150-200 m, the reservoir thickness in some areas of the reservoir reaches more than $30 \mathrm{~m}$.

The study involved 4 wells. In these wells, core samples were taken for X-ray phase analysis (XRD) to determine the mineral components.

To solve the problem of constructing a lithological model used geophysical well logging data and the results of laboratory core studies. Gamma-gamma density logging (GGL), neutron gamma logging (NGL), and gamma logging (GR) were chosen as the main methods for calculating the volume model. Resistivity logging (lateral logging) was used to calculate the saturation coefficient. To carry out logging data to uniform conditions, a double difference parameter was calculated for the NGL GR methods. After the calculations, the histograms of the density distribution and the double-difference parameter (INGL, IGR - gamma ray index) for the reference interval were constructed. It was noted that an adjustment should be made for one well for INGL and for one well for the GGL (Fig. 1,2). The introduction of an additive correction in both cases is associated with the technology of logging operations and tool errors.
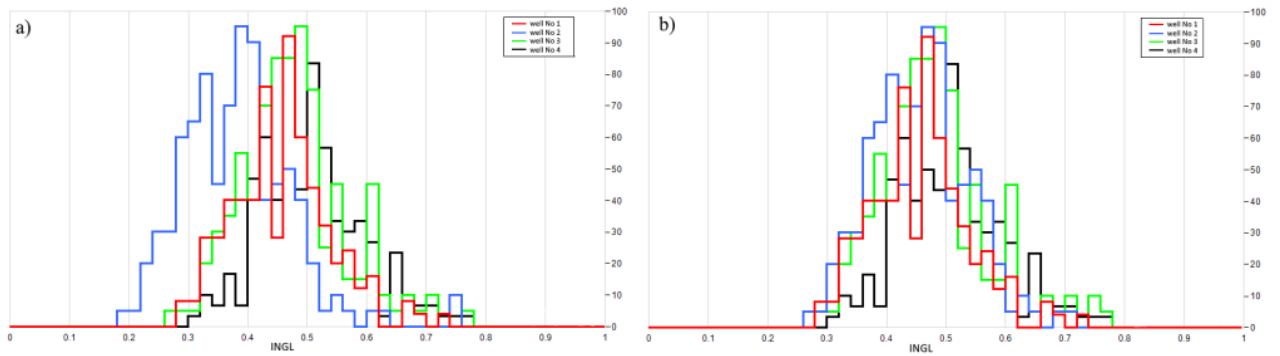

Fig.1. Histograms of the distribution of INGL in the reference interval before (a) and after (b) normalization.
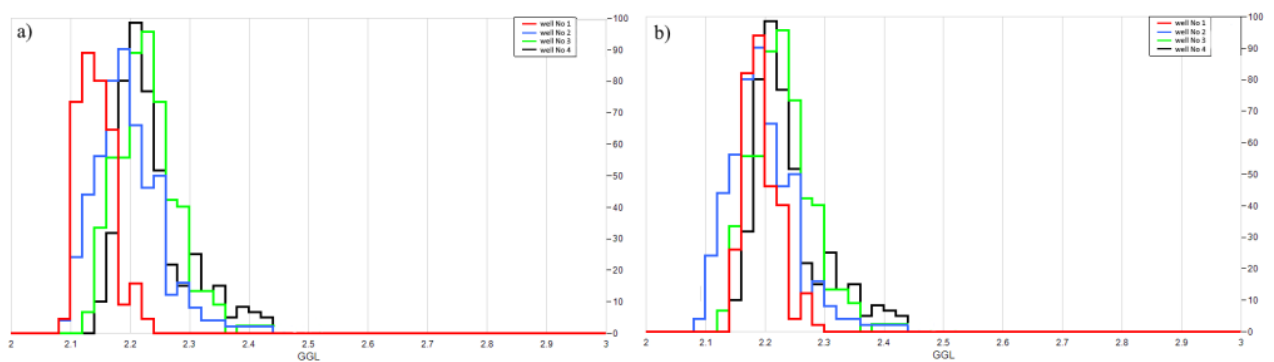

Fig.2. Histograms of the distribution of GGL in the reference interval before (a) and after (b) normalization.

At the stage of working with core data, samples were taken from the studied wells from the reservoir formation and overlying clays. The mineralogical composition was determined under laboratory conditions by X-ray phase analysis. The selected samples were ground into the consistency of powder. Then, studies were carried out in a diffractometer, which uses characteristic radiation, the source of which is an X-ray tube. After that, the interpretation of the captured diffractograms was carried out using the ASTM (American Society for Testing Materials) card file. 
The method of statistical reverse modeling (SRM), based on logging data, was used to estimate the volume content of mineral components. The solution of a system of linear equations is the basis of this method $[3,4]$ :

$$
f_{i}=\sum_{j=1}^{m} e_{i j} V_{j}, \quad i=1, n
$$

where $f_{i}$ is the logging method readings linearly related to the volume content of each component composing it, $e_{i j}$ is the theoretical value of the parameter $i$ for mineral $j, \mathrm{~V}_{\mathrm{j}}$ is the volume content of mineral $j, \mathrm{~m}$ is the number of volume components involved in the calculation.

The solution to the inverse problem may do using the statistical reverse modeling method. It is base on setting the uncertainty bounds for each required component. To determine the optimal solution, use the specified deviation between the recorded logging data and the theoretical values. The following equation use to determine this deviation [5, 6]:

$$
\Delta=\sqrt{\frac{1}{n} \sum_{i=1}^{n} \frac{\left(m_{i}-f_{i}\right)^{2}}{\tau_{i}^{2}+\delta_{i}^{2}}}
$$

where $n$ is the number of rock components, mi is the measured values of the geophysical parameter $i, f_{i}$ is the calculated values of the parameter $i, \delta_{i}$ is the deviation that characterizes the uncertainty of the values of the geophysical parameter $i$ of the rock component.

The statistical model is configured using a priori information. In this paper, X-ray phase studies of the core, data of the porosity, and density of rock samples were used to configure the model and evaluate the results of solving the inverse problem of determining the formation volume lithological model.

\section{Discussion of the results}

According to the results of X-ray phase analysis, the following mineral components are founding in sandstone rock samples: quartz, calcite, dolomite, mixed layer, pyrite, analcime, albite, clinochlore, mica, gypsum. Samples of clay and limestone formation have been studying. It should be noted that they also contain calcite and dolomite minerals, and analcime minerals are absent [7]. The presence of analcime was observed during electron microscope studies [2] in the places of leached calcite cement. This mineral is a feature of sandy bitumen-saturated reservoirs.

Not always redundant information gives a high-quality result. It is necessary to proceed from the available a priori data for the construction of the volumetric lithological model. In addition, the resulting statistical model should show a qualitative result in wells with limited a priori information. It was decided to group the mineral components obtained from the results of X-ray phase analysis. The grouping was carried out based on the physical properties of the minerals and the possibilities of geophysical methods for their identification [8]. We also identify components that will not be included in the model due to their small amount and rare occurrence in the samples according to the XRD results.

Table 1 shows the obtained component composition based on the results of laboratory studies using the XRD method and their grouping for statistical modeling of a volumetric lithological model.

Table 1. Model components.

\begin{tabular}{|c|c|c|c|c|}
\hline $\begin{array}{c}\text { Model } \\
\text { component }\end{array}$ & Quartz & Carbonate & Clay & $\begin{array}{c}\text { Others } \\
\text { (not included }\end{array}$ \\
\hline
\end{tabular}




\begin{tabular}{|c|c|c|c|c|c|c|c|c|c|c|c|}
\hline & & & & & & & & \multicolumn{4}{|c|}{ in the model) } \\
\hline $\begin{array}{c}\text { Mineral } \\
\text { (XRD) }\end{array}$ & $\begin{array}{l}\stackrel{N}{E} \\
\vec{Z}\end{array}$ & 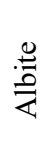 & $\begin{array}{l}\stackrel{\Xi}{0} \\
.0 \\
.0 \\
:\end{array}$ & $\frac{\frac{0}{0}}{\frac{\pi}{\pi}}$ & $\begin{array}{l}\stackrel{\mathscr{U}}{\Xi} \\
\frac{0}{0} \\
\stackrel{\circ}{\circ}\end{array}$ & 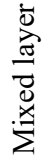 & $\stackrel{\mathscr{E}}{\Sigma}$ & 营 & $\begin{array}{l}0 \\
\stackrel{0}{0} \\
\bar{t} \\
0 \\
. \Xi \\
.0\end{array}$ & & 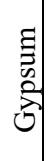 \\
\hline
\end{tabular}

The GR, NGL, and NGL were selected to configure the static modeling of the bulk lithological model. Modeling with acoustic logging showed similar convergence of the results. But it excluded from the main branch of the statistical model since it was recording in a limited number of wells in the studied field. The selection of the reference theoretical values was based on the core data for the selected components of the model, taking into account the results of studies of the studied field. It should be taken into account that each component of the model represents a group of minerals, and we have excluded some minerals from the simulation. These assumptions should be offset by the established delta. The selected reference values and delta values are shown in Table 2.

Table 2. Parameters of Statistical Reverse Model.

\begin{tabular}{|l|c|c|c|c|c|c|c|c|}
\hline & \multicolumn{2}{|c|}{ Clay } & \multicolumn{2}{c|}{ Carbonate } & \multicolumn{2}{c|}{ Sand } & \multicolumn{2}{c|}{ Porosity } \\
\hline \multicolumn{1}{|c|}{ Input } & End Pt. & Delta & End Pt. & Delta & End Pt. & Delta & End Pt. & Delta \\
\hline GGL & 2.4 & 0.05 & 2.7 & 0.05 & 2.6 & 0.05 & 1 & 0.01 \\
\hline INGL & 0.1 & 0.02 & 0.9 & 0.02 & 0.55 & 0.02 & 0 & 0.01 \\
\hline IGR & 1.3 & 0.05 & 0.25 & 0.05 & 0.1 & 0.05 & 0 & 0.05 \\
\hline
\end{tabular}

The saturation parameter was determined by the Dakhnov-Archi method according to the methodological data on the interpretation of bituminous deposits of the Republic of Tatarstan.

The use of a statistical approach in the interpretation of geophysical data of wells allowed us to reliably estimate the content of clay and carbonate matter, saturation, and porosity in the Permian deposits of the bituminous sand layer, which confirmed by the results of core studies. Figure 3 shows an example of the resulting volumetric lithological model for one of the wells. It is the comparison of the results with the core data.

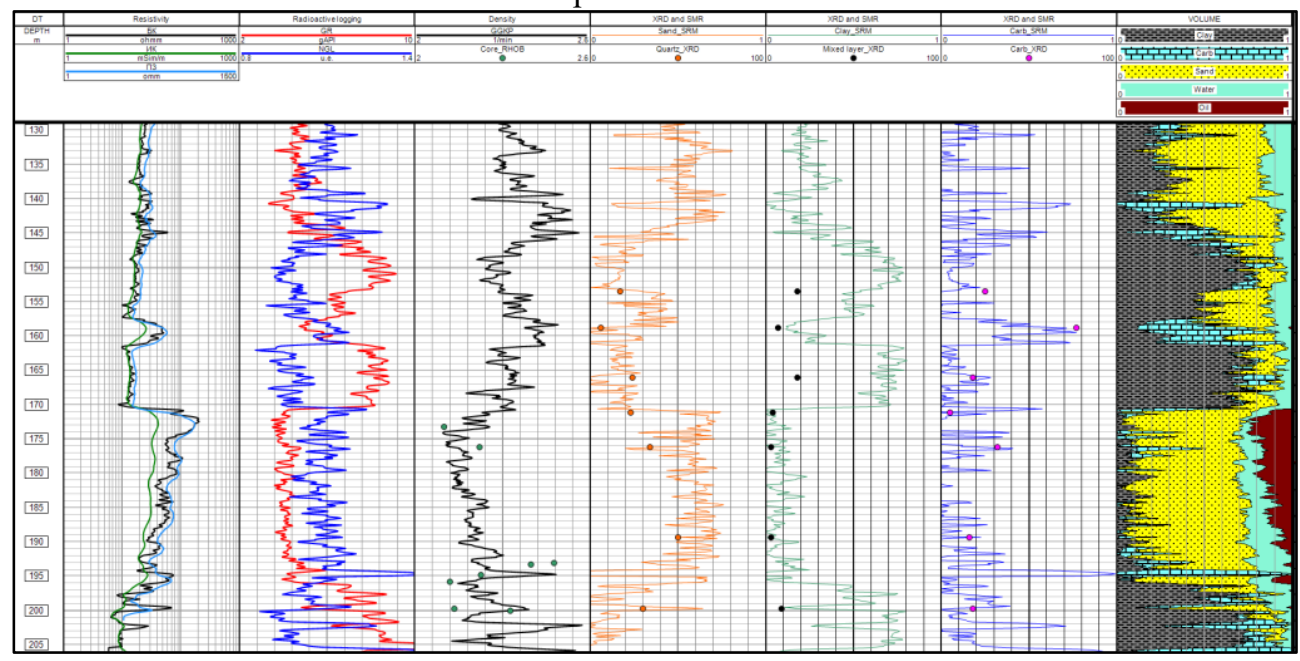

Fig.3. The statistical reverse model in one of wells and comparison with XRD core analysis data. 
The reservoir layer is represented by sand rocks according to the results of the interpretation. The content of the clay component on average of the layer reaches $5 \%$. The top and bottom part of the formation is compacted, and the rock contains carbonate cement. The middle part of the formation is represented by unconsolidated sand with an insignificant content of clay fraction. The results obtained correlate with the XRD data on the amount of minerals such as quartz, carbonate component, and clay components.

The clay layer, which is the cover of the reservoir layer, is divided into two parts by a limestone layer. The simulation results also revealed this formation. By comparing the synthetic curves with the core data, we can see a good correlation in the content of the simulated components.

In the works of researchers, the zonality of the studied reservoir is noted $[7,9,10]$, which consists of the heterogeneity of the reservoir in depth. According to the results of core studies by the X-ray phase method and logging data using the SRM of constructing a volume model, this zoning is also traced. The reservoir layer is heterogeneous in depth.

\section{Conclusion}

The article presents the results of volumetric lithological statistical reverse modeling. This approach allows not only to evaluate the petrophysical properties of the reservoir. But also to significantly increase the information content and accuracy of predictive estimates of the filtration and reservoir properties of the productive reservoir. The application of this method is important for the study of natural bitumen reservoirs composed of weakly cemented and loose sandstones. Since laboratory studies of such rocks on standard cylindrical samples face significant difficulties and can lead to erroneous results, therefore, the correlation of laboratory core data and GIS data becomes, in some cases, impossible. Therefore, the proposed approach of setting up the model taking into account the studies of powdered samples for XRD allows us to solve this problem to some extent..

The reported study was funded by RFBR, project number 19-35-90045

\section{References}

1. R. C. Khisamov, M. M. Musin, K. M. Musin, I. N. Fayzullin, A. T. Zaripov, Obobshenie rezyltatov laboratornukh I oputno-promushlennukh rabot po izucheniy sverkhvyazkoy nefti iz plasta (Academiya nayk RT,Fen, 2013)

2. E. Korolev, V. Sudakov, D. Nikolaev, R. Gabdelvalieva, S. Usmanov, International Multidisciplinary Scientific GeoConference: SGEM, 18 (1-1), 489 (2018)

3. W. K. Mitchell, R. J. Nelson, World Oil, 212 (6) (1991)

4. Moses, B., and R. Harrison, SPE Offshore Europe, OnePetro (1985)

5. W. K. Mitchell, R. J. Nelson, A practical approach to statistical log analysis (SPWLA 29th, 1988)

6. P. Kulyapin, T. F. Sokolova, Technologii seismorazvedki, 3, 28, (2013)

7. E. A. Yachmeneva, V. E. Kosarev, D. I. Khassanov, G. M. Eskina, SGEM, 19 (1-1), 601 (2019)

8. G. Wang, T. R. Carr, Y. Ju, SPE Unconventional Resources Conference. Society of Petroleum Engineers (2014)

9. N.G. Nurgalieva, N.A. Ikhsanov, D.K. Nurgaliev, A.N. Daytov, Oil Industry, 4, 72 (2016) 
10. E. A. Yachmeneva, D. I. Khassanov, International Multidisciplinary Scientific GeoConference: SGEM 20 (1-1), 125 (2020) 